\title{
Risk factors for loco-regional recurrence in breast cancer patients: a retrospective study
}

\author{
Tomás Merino ${ }^{1, *}$, Teresa Ip $^{1, *}$, Francisco Domínguez ${ }^{2}$, Francisco Acevedo ${ }^{1}$, Lidia \\ Medina ${ }^{1}$, Alejandra Villaroel ${ }^{3}$, Mauricio Camus ${ }^{2}$, Eugenio Vinés ${ }^{1}$ and César Sánchez ${ }^{1}$ \\ ${ }^{1}$ Department of Hematology-Oncology, Pontificia Universidad Católica de Chile, Santiago, Chile \\ ${ }^{2}$ Department of Surgery, Pontificia Universidad Católica de Chile, Santiago, Chile \\ ${ }^{3}$ Department of Pathology, Pontificia Universidad Católica de Chile, Santiago, Chile \\ *These authors contributed equally to this work \\ Correspondence to: Tomás Merino, email: tmerino@med.puc.cl \\ Keywords: breast cancer; local recurrence; regional recurrence; predictors; subtype \\ Received: January 29, $2018 \quad$ Accepted: June 23, $2018 \quad$ Published: July 13, 2018 \\ Copyright: Merino et al. This is an open-access article distributed under the terms of the Creative Commons Attribution License \\ 3.0 (CC BY 3.0), which permits unrestricted use, distribution, and reproduction in any medium, provided the original author and \\ source are credited.
}

\section{ABSTRACT}

Background: Although fairly uncommon, loco-regional recurrence in breast cancer (BC) has major consequences for the patient. Several predictors for locoregional have been previously reported from large randomized clinical trials mainly from Europe \& North America; data from other geographical areas are somewhat scarce. Here we performed a retrospective review of medical records in a single academic center in Chile, searching for predictors of breast tumor recurrence.

Results: Median patient follow up was 61 months, 5 year overall survival (OS) rate was $94.2 \%$ (95\% CI 93-95.3). We found that 108 out of $2,754(5.3 \%)$ patients had loco-regional recurrence. The 2-year loco-regional control was $98 \%$ (95\% CI 97.3-98.7) and 5-year was $94 \%$ (95\% CI 92.6-95.4). Univariate analysis showed a correlation between recurrence and being $<50$ year-old, positive surgical margins, advanced stage, subtype, and presence of LVI and omission of adjuvant radiotherapy. Only the absence of adjuvant RT was predictor of locoregional recurrence in multivariable $(p<0.001)$.

Materials and Methods: We analyzed medical records from 2,201 BC patients at the Pontificia Universidad Católica de Chile from 1997 to 2016. Collected data included: age at diagnosis, tumor size, axillary involvement, molecular subtype, margin status, histological grade, lympho-vascular invasion (LVI) and ipsilateral recurrence.

Conclusions: Our study population presents high local control of BC. Age, surgical margins, stage, molecular subtype and absence of adjuvant radiotherapy were associated with loco-regional recurrence. Prospective trials and long-term follow up are required in order to confirm these results.

\section{INTRODUCTION}

For decades, mastectomy has been both the most common surgical treatment for stage I/II breast cancer $(\mathrm{BC})$ and the preferred treatment for loco-regional disease. Alternatively, treatments may also consist in a combination of breast conserving surgery (BCS) plus radiotherapy (RT). Indeed, several prospective randomized clinical trials have demonstrated that this combination approach provides local control and patient survival rates equivalent to those observed with mastectomy [1].

Nevertheless, about $17 \%$ of patients treated with BCS plus RT develop ipsilateral breast tumor recurrence (IBTR) within 20 years of treatment [2]. The IBTR risk is the highest during the first 5 years following treatment, with an incidence rate of 5-10\% [3]. Furthermore, patients that developed IBTR or loco-regional recurrence (LRR) have a significantly poorer prognosis [4]. 
Over the last decades, significant advances in systemic treatments along with a new classification of $\mathrm{BC}$ subtypes have increased the interest for predictors of recurrence in $\mathrm{BC}$ patients that have received treatments.

Several studies conducted in Europe and North America have analyzed clinical and histopathologic factors associated to an increased risk of $\mathrm{BC}$ recurrence. However, to the best of our knowledge such studies are yet to be reported in the Chilean population. Therefore, the aim of our study was to identify risk factors for loco-regional breast tumor recurrence in Chilean women with invasive BC.

\section{RESULTS}

\section{Patient characteristics}

A total of 2,754 patients were treated for BC in the period 1997-2016, within this group 2,201 had information about local control and were included into this study. Patient median follow up time for OS was 61 months. Median follow up for local control was 32.6 months (range 0-285). Main characteristics of patients, tumor and received treatments are summarized in Table 1. As shown in Figure 1A 5-year OS was 94.2\% (95\% CI 93-95.3).

\section{Locoregional control}

Figure 1B shows that 2-year LRC was 98\% (95\% CI 97.3-98.7) and 5-year was 94\% (95\% CI 92.6-95.4). Overall, 108 out of 2,198 (5.3\%) patients displayed BC recurrence, with a median time of recurrence: 66 months after surgery. The site of recurrence was available in 50 cases, and the most frequent site was the same quadrant of the breast $(N=18)$, followed by chest wall (14), and the axila (8), SCV was the first local recurrence in 6 patients, 3 presented a recurrence in the same breast but in a different quadrant and 1 had an internal mammary recurrence.

\section{Predicting loco-regional recurrence}

A summary of the results of an univariate analysis for loco-regional recurrence is shown in Table 2. Briefly, locoregional control at 2 and 5 years were $98 \%$ (95\% CI 96.8 $99.1)$ and $91 \%$ (95\% CI 88-93.9) respectively for patients aged $<50$. For patients that were $\geq 50$ years these values were $98 \%$ (95\% CI 97-98.9) and 96\% (95\% CI 94.6-97.4), respectively (Figure 2A. $p=0.0013$ ). Loco-regional control by surgical margin status is presented in Figure 2B. Univariate analysis showed that age, surgical margin status, lymphovascular invasion (LVI), breast cancer subtype, advanced stage (Stage III or IV) were predictors of regional recurrence.

A Kaplan Meier analysis is shown in Figure 2C. LRR rates at 2 and 5 years were 99\% (95\% CI 98.2-99.7) and 97\% (95\% 94.8-99.1) without LVI; and 97\% (95\% CI 95.2-98.7) and 90\% (95\% CI 86.2-93.7) respectively with LVI $(p=0.001)$.
Next, LRC rates according to BC subtypes were analyzed. Within the luminal A subtype LRC rates at 2 and 5 years were $99.4 \%$ (95\% CI 98.8-99.9) and 98.3\% (95\% CI 97.1-99.4) respectively. For luminal B, LRC at 2 and 5 years were $94.6 \%$ (95\% CI 96-99.1) and 93.1\% (95\% CI 90.1-96). For HER2 enriched, LRC at 2 and 5 years were $92.5 \%$ (95\% CI56-98.9) and 88.2\% (95\% CI 79.7-96.6). Finally, for triple negative, LRC rates at 2 and 5 years were $94.9 \%$ (95\% CI 91.3-98.4) and 88.3\% (95\% CI 82.6-93.9), (Figure 3A).

Compared with Luminal A type, we obtained significant difference for all the subtypes $(p<0.001)$. With Luminal B (HR 2.875; 95\% IC 1.64-5.05), HER2 positive (HR 5.88; 95\% CI 2.74-12.65), triple negative (HR 4.496; 95\% CI 2.3-8.5) $p \leq 0.001$. If grouped together, Luminal A compared with non Luminal A (HR 0.281 ; 95\% CI $0.17-$ $0.47 ; p<0.001$ ) favors Luminal A type $p<0.001$, Figure 3B.

Notably, no association was found between risk of loco-regional recurrence and type of surgery $(p=0.43)$ or adjuvant chemotherapy ( $p=0.978$, Figure $4 \mathrm{~A})$. Conversely, adjuvant hormonotherapy (HR 0.418; 95\% CI 0.27-0.65; $p<0.001$, Figure 4B) or adjuvant RT 0.27 (0.17-0.42) $p<0.001$, Figure 4C), were associated to better disease control. Patients at risk by subgroup is presented in Supplementary Table 1.

Patient who didn't receive adjuvant hormone therapy had higher LRC than those who did. The LRC rate at 2 and 5 years were 93.8\% (95\% CI 90.6-96.9\%) and $88.8 \%$ (95\% IC 84.2-93.3\%) and 98.9\% (95\% CI 98.1-99.6) and 95.8\% (95\% CI 94.2-97.3) respectively $p<0.001$. Adjuvant RT, also favored LRC control. The LRC at 2 and 5 years were $89.7 \%$ (95\% CI 84.6-94.8) and $83.6 \%$ (95\%CI 76.7-90.4) for those without RT and 98.8\% (95\% CI 98.2-99.4) and 95.8\% (95\% CI 94.4-97.1) for those with adjuvant RT $p<0.001$.

The use of adjuvant chemotherapy was not associated to local recurrence $(p=0.978)$.

Finally, variables that were statistically significant $(p<0.05)$ were then entered into the multivariate analysis, however as shown in Table 3 only the absence of adjuvant RT maintained statistical significance: (HR 6.588: 95\% CI $2.1-19.9 ; p<0.001)$.

\section{DISCUSSION}

In this study, we evaluated risk factors that determine loco-regional $\mathrm{BC}$ recurrence in a Chilean group of patients. To the best of our knowledge this is the first and the largest study of its kind in Chile.. Our study covers a long period of time of almost two decades (19 years), over this period we have seen significant advances in $\mathrm{BC}$ treatment. Evidently, local recurrence is a rather infrequent event, unless it is measured over a longer time period in order to capture a larger number of events, thereby introducing some heterogeneity into the collected data. 
Table 1: Patient, tumor and treatment characteristics

\begin{tabular}{|c|c|c|}
\hline Characteristic & $N$ & Median/(Range) \\
\hline Age & 2198 & $55 /(19-101)$ \\
\hline Characteristic & $N$ & $\%$ \\
\hline \multicolumn{3}{|l|}{ Breast surgery } \\
\hline Lumpectomy & 1467 & 66.7 \\
\hline Mastectomy & 593 & 26.9 \\
\hline Unknown & 141 & 6.4 \\
\hline \multicolumn{3}{|l|}{ Axillar surgery } \\
\hline SLND & 985 & 44.8 \\
\hline $\mathrm{AD}$ & 1016 & 46.2 \\
\hline Unknown & 200 & 9.1 \\
\hline \multicolumn{3}{|l|}{ Tumor Stage } \\
\hline 1 & 814 & 37 \\
\hline 2 & 804 & 36.5 \\
\hline 3 & 367 & 16.7 \\
\hline 4 & 46 & 2.1 \\
\hline Unknown & 170 & 7.7 \\
\hline \multicolumn{3}{|l|}{ Tumor Subtype } \\
\hline Luminal A & 951 & 43.2 \\
\hline Luminal B & 585 & 26.6 \\
\hline HER2-enriched & 117 & 5.3 \\
\hline Triple-negative & 225 & 10.2 \\
\hline Unknown & 323 & 14.7 \\
\hline \multicolumn{3}{|l|}{ Margins } \\
\hline Positive & 90 & 4.1 \\
\hline Negative & 671 & 30.5 \\
\hline Unknown & 1440 & 65.4 \\
\hline \multicolumn{3}{|l|}{ Vascular invasion } \\
\hline Positive & 540 & 24.5 \\
\hline Negative & 563 & 25.6 \\
\hline Unknown & 1098 & 49.9 \\
\hline \multicolumn{3}{|c|}{ Adjuvant Chemotherapy } \\
\hline No & 857 & 38.9 \\
\hline Yes & 897 & 40.8 \\
\hline Unknown & 447 & 20.3 \\
\hline \multicolumn{3}{|c|}{ Adjuvant Radiotherapy } \\
\hline No & 185 & 8.4 \\
\hline Yes & 1375 & 62.5 \\
\hline Unknown & 641 & 29.1 \\
\hline \multicolumn{3}{|c|}{ Adjuvant Hormonotherapy } \\
\hline No & 285 & 12.9 \\
\hline Yes & 1005 & 45.7 \\
\hline Unknown & 911 & 41.4 \\
\hline
\end{tabular}

Abbreviations: SLND: sentinel lymph node dissection. AD: axillar dissection. 
Table 2: Univariate analysis

\begin{tabular}{lcc}
\hline Variable & HR $($ IC) & $p$ \\
\hline Age $<50$ & $1.58(1.096-2.28)$ & 0.0013 \\
Margin \pm & $2.57(1.00-6.58)$ & 0.049 \\
Stage II vs I & $1.62(0.96-2.76)$ & $\mathrm{NS}$ \\
Stage III vs I & $2.98(1.69-5.3)$ & $<0.001$ \\
Stage IV vs I & $12.98(4.86-34.7)$ & $<0.001$ \\
BCS vs MT & $0.85(0.57-1.27)$ & $\mathrm{NS}$ \\
LV invasion + & $2.99(1.52-5.9)$ & 0.001 \\
Luminal B vs LA & $2.87(1.64-5.05)$ & $<0.001$ \\
Her2 + vs LA & $5.88(2.74-12.65)$ & $<0.001$ \\
Triple neg vs LA & $4.49(2.3-8.5)$ & $<0.001$ \\
Non-LA vs LA & $3.56(2.14-5.92)$ & $<0.001$ \\
HT vs no HT & $0.42(0.27-0.65)$ & $<0.001$ \\
RT vs no RT & $0.27(0.17-0.42)$ & $<0.001$ \\
No ACT vs ACT & $1.0(0.67-1.51)$ & $\mathrm{NS}$ \\
\hline
\end{tabular}

Abbreviations: $\mathrm{BCS}=$ breast conserving surgery, $\mathrm{MT}=$ Mastectomy, $\mathrm{LV}=$ lymphovascular invasion, $\mathrm{LA}=$ Luminal A, Triple neg $=$ Triple negative, Non-LA = non luminal A subtype (LB, triple neg and Her2+ combined) HT $=$ Hormonal therapy, $\mathrm{RT}=$ Radiotherapy, ACT $=$ Adjuvant chemotherapy.

Indeed, first we explored potential differences in locoregional recurrence over two time periods $1997-2004$ vs 2004-2016 and we did not find significant differences (not shown, Log rank 0.197).

Our data show that 5 -year LRR control rate was $94 \%$, similar to previous reports [5]. Also in agreement with previous studies loco-regional control was better in older patients ( $>50$ year-old) [6-7]. Similarly, positive surgical margin status is commonly associated to an

A

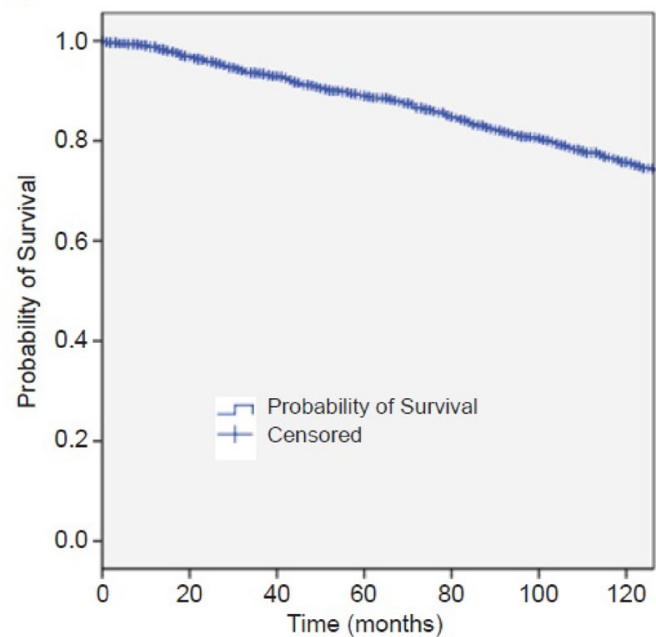

No. At risk

\begin{tabular}{ccccccc}
0 & 20 & 40 & 60 & 80 & 100 & 120 \\
\hline 2198 & 1641 & 1307 & 1082 & 889 & 707 & 537
\end{tabular}

increase in the risk of, ipsilateral breast recurrence (HR 2.51) [8], and poorer prognoses.

Regarding BC subtypes, HER2+ was associated to higher LRR rates, again confirming published results from the literature [9-10] and suggesting a poor response of this subtype to conventional therapies. However, the use of trastuzumab in these patients improves clinical outcomes and increases the sensitivity to RT [11-12]. Our institution incorporated trastuzumab in 2011 when it became covered by medical insurance in our country.

B

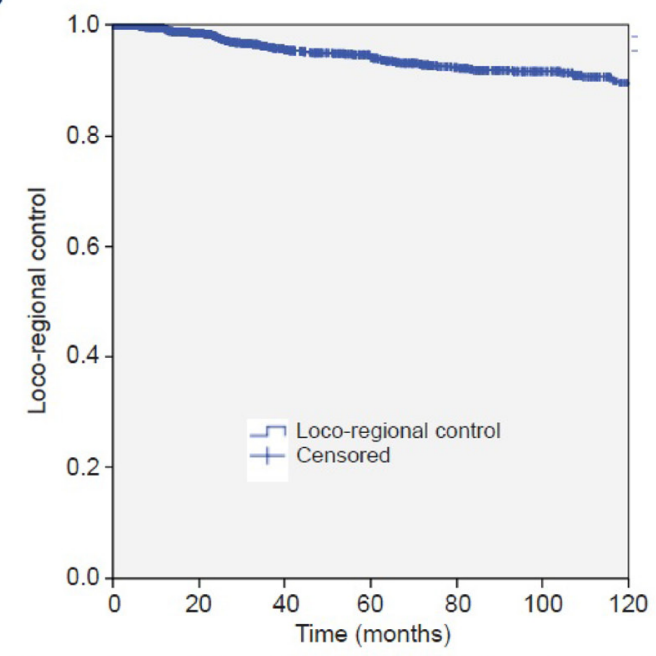

\begin{tabular}{lccccccc} 
No. At risk & 0 & 20 & 40 & 60 & 80 & 100 & 120 \\
\cline { 2 - 7 } & 2178 & 1314 & 976 & 786 & 567 & 421 & 281
\end{tabular}

Figure 1: Overall survival rates (A) and loco-regional disease control (B). 
Previous studies have suggested a relationship between $\mathrm{BC}$ subtypes and response rate to RT. Indeed, Luminal A is usually associated to better response; in contrast HER2+ cancers are considered less responsive to RT [13]. Despite this, a recent randomized trial demonstrates that $\mathrm{BC}$ subtype was not predictive of RT response, similar to our results (not shown).

Along the years of the study, RT was administered using two regimens: standard treatment, that consists of a 50 Gy dose in 25 daily fractions over 5 weeks; or hypofractionated, consisting on 15-16 fractions over 3 weeks, with or without a boost. Adjuvant RT in our study had an impact on loco-regional control, HR 0.269
(95\% CI $0.172-0.42)$, as reported previously [14]. The most frequent sites of loco-regional recurrence were the breast and the chest wall followed by the supraclavicular and the axilla. One patient displayed regional recurrence in internal mammary.

Our univariate analysis showed significant associations between age, surgical margin, stage, molecular subtype, LVI status and adjuvant RT with LRR but multivariate analysis was the only variable significantly associated with local recurrence. Despite these results, our findings must be interpreted cautiously, mainly due to a relatively small number of cases/events and the amount of missing/lost data. In addition to this, our study has a number
A

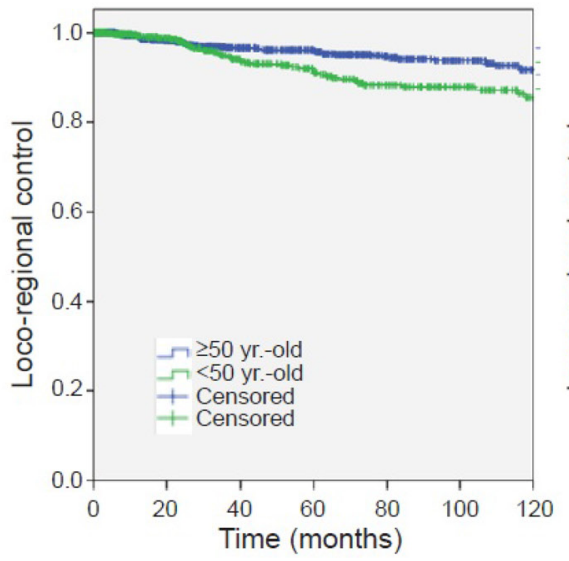

B

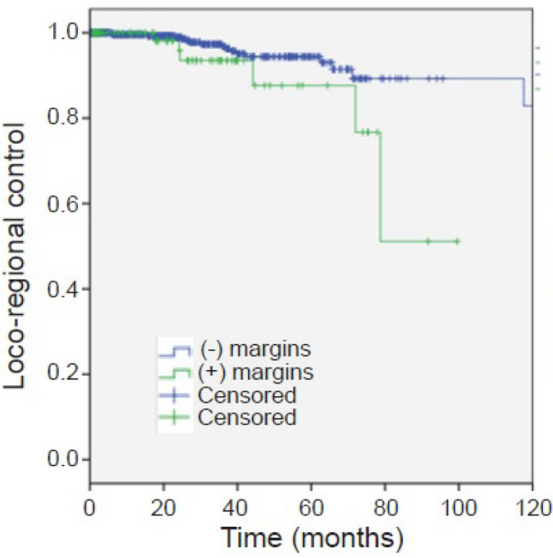

C

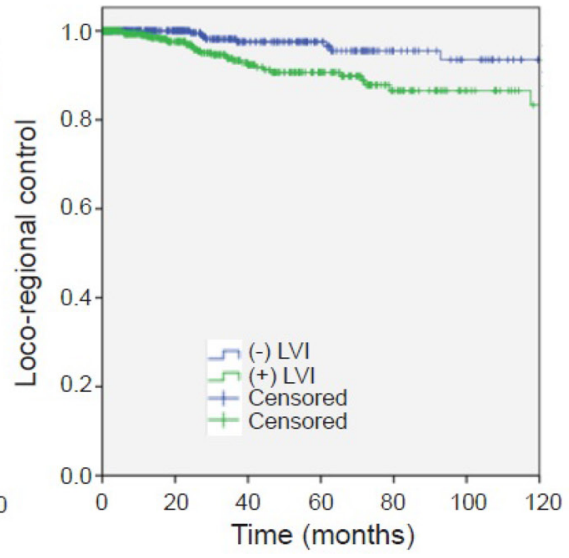

Figure 2: Loco-regional control of disease. (A) by Age. (B) by Margin status, and (C) by lymphovascular Invasion (LVI).

A

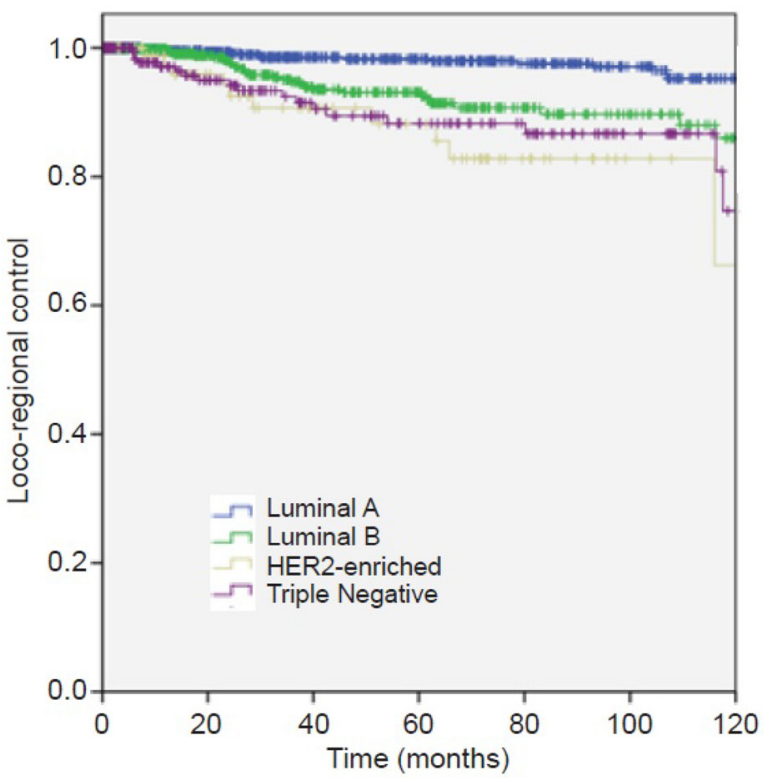

B

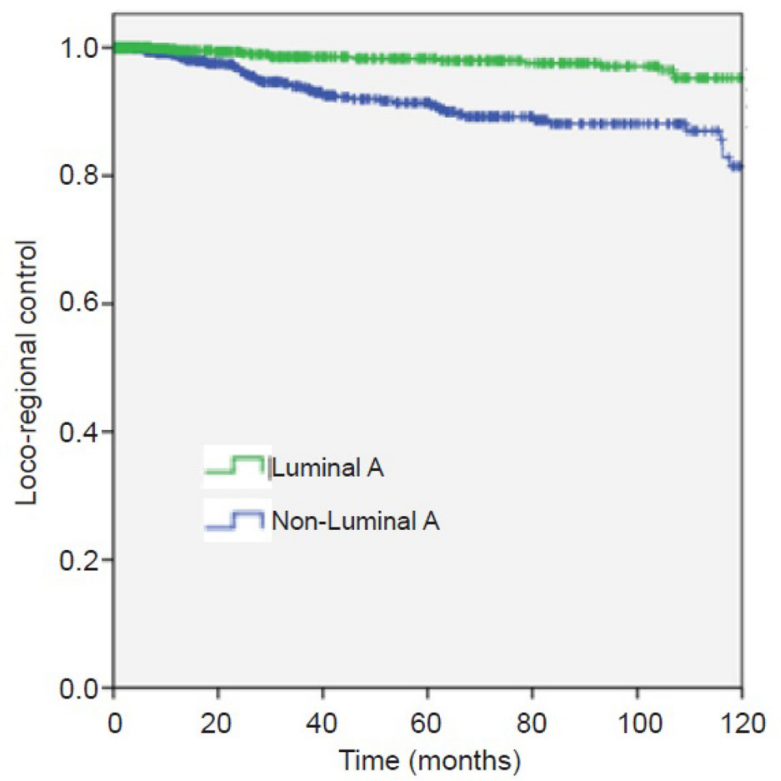

Figure 3: Loco-regional control of disease (A) by breast cancer subtype. (B) by breast cancer subtype comparing luminal A versus nonluminal A. 
of other limitations: first, it is a retrospective study based at a single center, second the recruiting period time was long enough (almost 20 years) to experience changes in classifications and standard treatments, the incorporation of subtype was based on modified UC criteria, third biopsies were done by local pathologists and we did not have a centralized pathology review. Some patient information regarding chemotherapy schemes, hormone therapy and RT was either not available or highly heterogeneous in some cases. Finally, there is a possibility that some patients might have had follow ups or receive treatments in other medical centers, in these cases recurrent disease could not have been recorded, all these limitations have to be considered and therefore the interpretation of our results should be done with caution.

\section{MATERIALS AND METHODS}

\section{Study design}

This was a retrospective study of the medical records of invasive BC patients treated between 1997 and 2016 at the Pontificia Universidad Católica de Chile and the Red de Salud UC Christus.

Our study was performed in compliance with the Declaration of Helsinki. All procedures, along with permission to access the databases were approved by the local research ethics committee at the Pontificia Universidad Católica de Chile. Due to the retrospective and therefore non-interventional nature of this study no written informed consent were requested by the local research committee.

Patients were included if they were treated for invasive $\mathrm{BC}$ regardless of histology type, or any kind of surgery (Mastectomy or BCS) for their primary and adjuvant treatments according to local guidelines. Patients with no information on loco-regional BC recurrence were excluded.
Patient characteristics were assessed at the time of diagnosis and included: age, tumor size, axillary involvement, margin status (negative margin was defined by no ink on tumor) and lympho-vascular invasion.

Pathological reports from the primary tumor were reviewed regarding histological type, tumor size, nodal compromise and histological grade, according to Elston \& Ellis [15]. Receptor status was determined via immunohistochemistry. Estrogen and progesterone receptors (ER and $\mathrm{PR}$ respectively) were defined as positive when $\geq 1 \%$ of tumor cells showed nuclear positive staining. Tumors that had a HER2 score of 3+ were considered HER2+ [16]. For HER2 2+, a fluorescence in situ hybridization study was done. Since in our center $\mathrm{Ki} 67$ is not routinely indicated, it was excluded from our analyses. Tumor stage was determined according to the guidelines of the American Joint Committee on Cancer 7th [17]. Tumors were classified into 4 subtypes according to immunohistochemistry markers and histological grade, as described [18]. Luminal A (ER+ and/or PR+, HG 1-2, HER2-), Luminal B (ER+ and/or PR+, HG 3 and/ or HER2+), triple negative (ER-, PR- and HER2-) and HER2-enriched (ER- and PR-, HER2+).

Patients were treated according to local guidelines. Briefly, early stage BC were treated with BCS and RT. Loco-regional advanced $\mathrm{BC}$ were treated with mastectomy with or without adjuvant RT or neoadjuvant chemotherapy followed by breast surgery and RT. Patients with clinically negative axilla has sentinel lymph node dissection, if this was positive, patient has axillary dissection. Radiotherapy dosing was 50 Gy in 25 fractions to the breast/chest wall \pm regional lymph nodes if indicated. Boost was $10 \mathrm{~Gy}$ in 5 fractions. Since 2010 an increasing percentage of early stage $\mathrm{BC}$ have been treated with hypofractionated RT of $42.5 \mathrm{~Gy}$ in 16 fractions.

All patient cases were discussed at a breast multidisciplinary board in order to decide the best adjuvant
A

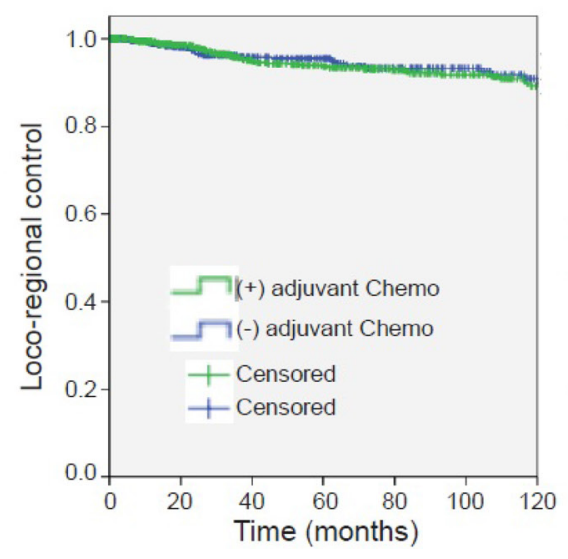

B

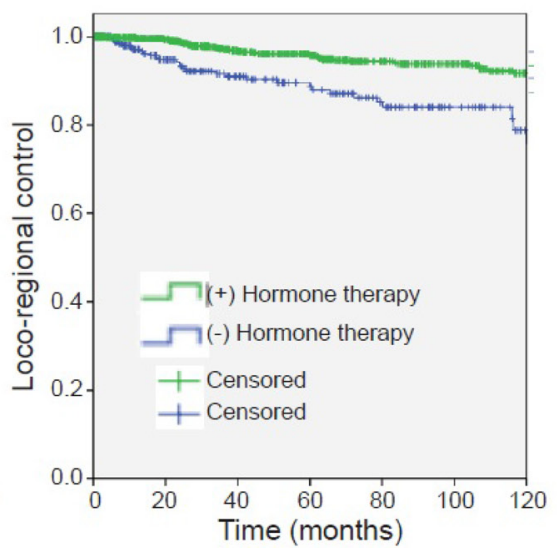

C

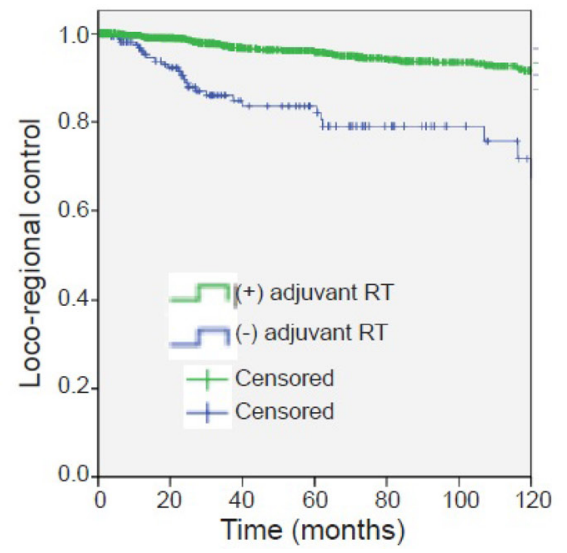

Figure 4: Loco-regional control of disease. (A) in patients with or without adjuvant chemotherapy. (B) in patients with or without hormone therapy. (C) in patients with or without adjuvant radiotherapy (RT). 
Table 3: Multivariate analysis

\begin{tabular}{lcc}
\hline Multivariate & $\boldsymbol{p}$ & HR (95\% CI) \\
\hline Age $<$ 50 years & 0.823 & $1.1(0.4-2.8)$ \\
Positive surgical margins & 0.2 & $2.163(0.6-7.1)$ \\
Positive lymphovascular permeations & 0.213 & $2.171(0.6-7.3)$ \\
Stage I vs. & - & - \\
Stage II & 0.923 & $1.06(0.3-4)$ \\
Stage III & 0.099 & $3.246(0.8-13.1)$ \\
Stage IV & 0.152 & $5.45(0.5-55-5)$ \\
Luminal A & 0.193 & $0.482(0.2-1.4)$ \\
No adjuvant RT & 0.001 & $6.588(2.1-19.9)$
\end{tabular}

treatment. Chemotherapy was recommended for patients with a $>1.0 \mathrm{~cm}$ diameter triple negative $\mathrm{BC}$, and for $\mathrm{ER}+$ $\mathrm{BC}$ with extensive positive axilla. Trastuzumab was recommended for HER2+ BC. Radiotherapy was indicated for patients with BCS and patients with mastectomy and + lymph nodes.

Follow-up time started at the day of diagnosis. Patients were followed-up every three months during the first year, every four months during the second year, and every six months at the third to fifth year and then yearly. Clinical examination was performed in every visit. Mammography was performed yearly for patients with BCS, breast ultrasound was added for patients with a dense breast.

\section{Statistical analysis}

Loco-regional failure was defined as any evidence of recurrence in the same breast or regional lymph nodes (including axillary, supraclavicular or internal mammary). The Kaplan-Meier method was used for survival analysis. For univariate analysis log rank test was used. Exploratory subgroup analysis was done for age ( $<50$ years), positive margins, vascular invasion, AJCC stage, molecular surrogate subtype, adjuvant hormonal therapy, adjuvant chemotherapy, type of breast surgery

We used Cox proportional hazard regression model for multivariate analysis. Data analysis was performed using IBM SPSS version 19.

\section{CONCLUSIONS}

To date, this is the largest study that assesses BC recurrence risk factors and OS in Chilean women. Our data obtained from an academic center suggest a high loco-regional control rate in patients (>94\%). As expected, patients that were: $<50$-year-old, had positive surgical margins, advanced stage, a non-Luminal A subtype, had LVI or did not receive adjuvant RT had an increased risk for LRR. Future prospective and multicentric studies with long-term follow up periods should expand and confirm our findings.

\section{CONFLICTS OF INTEREST}

None.

\section{REFERENCES}

1. Morrow M, Strom EA, Bassett LW, Dershaw DD, Fowble B, Giuliano A, Harris JR, O'Malley F, Schnitt SJ, Singletary SE, Winchester DP; American College of Radiology; American College of Surgeons; Society of Surgical Oncology; College of American Pathology. Standard for breast conservation therapy in the management of invasive breast carcinoma. CA Cancer J Clin. 2002; 52:277-300.

2. Fisher B, Anderson S, Bryant J, Margolese RG, Deutsch M, Fisher ER, Jeong JH, Wolmark N. Twenty-year follow-up of a randomized trial comparing total mastectomy, lumpectomy, and lumpectomy plus irradiation for the treatment of invasive breast cancer. N Engl J Med. 2002; 347:1233-41.

3. Recht A, Silen W, Schnitt SJ, Connolly JL, Gelman RS, Rose MA, Silver B, Harris JR. Time-course of local recurrence following conservative surgery and radiotherapy for early stage breast cancer. Int J Radiat Oncol Biol Phys. 1988; 15: 255-61.

4. Wapnir IL, Anderson SJ, Mamounas EP, Geyer CE, Jeong JH, Tan-Chiu E, Fisher B, Wolmark N. Prognosis after ipsilateral breast tumor recurrence and locoregional recurrences in five National Surgical Adjuvant Breast and Bowel Project node-positive adjuvant breast cancer trials. J Clin Oncol. 2006; 24: 2028-37.

5. Clarke M, Collins R, Darby S, Davies C, Elphinstone P, Evans V, Godwin J, Gray R, Hicks C, James S, MacKinnon E, McGale P, McHugh T; Early Breast Cancer Trialists' Collaborative Group (EBCTCG). Effects of radiotherapy and of differences in the extent of surgery for early breast cancer on local recurrence and 15-year survival: An overview of the randomised trials. Lancet. 2005; 366:2087-106.

6. Fourquet A, Campana F, Zafrani B, Mosseri V, Vielh P, Durand JC, Vilcoq JR, Amalric R, Santamaria F, Robert F, Seigle J, Altschuler C, Kurtz JM, et al. Prognostic factors of 
breast recurrence in the conservative management of early breast cancer: a 25-year follow-up. Int J Radiat Oncol Biol Phys. 1989; 17:719-25.

7. Fowble BL, Schultz DJ, Overmoyer B, Solin LJ, Fox K, Jardines L, Orel S, Glick JH. The influence of young age on outcome in early stage breast cancer. Int J Radiat Oncol Biol Phys. 1994; 30:23-33.

8. Bodilsen A, Bjerre K, Offersen B, Vahl P, Mele M, Dixon M, Ejlertsen B, Overgaard J, Christiansen P. Abstract S2-01: Importance of margin width and re-excision in breast conserving treatment of early breast cancer; a Danish breast cancer cooperative group study of 11,900 women. Cancer Res. 2016; 76:S2-01.

9. Wang SL, Li YX, Song YW, Wang WH, Jin J, Liu YP, Liu XF, Yu ZH. Triple-negative or HER2-positive status predicts higher rates of locoregional recurrence in nodepositive breast cancer patients after mastectomy. Int J Radiat Oncol Biol Phys. 2011; 80:1095-101.

10. Voduc KD, Cheang MC, Tyldesley S, Gelmon K, Nielsen TO, Kennecke H. Breast cancer subtypes and the risk of local and regional relapse. J Clin Oncol. 2010; 28: 1684-91.

11. Horton JK, Halle J, Ferraro M, Carey L, Moore DT, Ollila D, Sartor CI. Radiosensitization of chemotherapyrefractory, locally advanced or locally recurrent breast cancer withtrastuzumab: a phase II trial. Int J Radiat Oncol Biol Phys. 2010; 76: 998-1004.

12. Panoff JE, Hurley J, Takita C, Reis IM, Zhao W, Sujoy V, Gomez CR, Jorda M, Koniaris L, Wright JL. Risk of locoregional recurrence by receptor status in breast cancer patients receiving modern systemic therapy and postmastectomy radiation. Breast Cancer Res Treat. 2011; 128:899-906.

13. Sjöström M, Lundstedt D, Hartman L, Holmberg E, Killander F, Kovács A, Malmström P, Niméus E, Werner
Rönnerman E, Fernö M, Karlsson P. Response to Radiotherapy After Breast-Conserving Surgery in Different Breast Cancer Subtypes in the Swedish Breast Cancer Group 91 Radiotherapy Randomized Clinical Trial. J Clin Oncol. 2017; 35:3222-3229.

14. Darby S, McGale P, Correa C, Taylor C, Arriagada R, Clarke M, Cutter D, Davies C, Ewertz M, Godwin J, Gray R, Pierce L, Whelan T, et al. Effect of radiotherapy after breast-conserving surgery on 10-year recurrence and 15-year breast cancer death: Meta-analysis of individual patient data for 10801 women in 17 randomized trials. Lancet. 2011; 378: 1707-16.

15. Elston CW, Ellis IO. Pathological prognostic factors in breast cancer. I. The value of histological grade in breast cancer: experience from a large study with long-term follow-up. Histopathology. 1991; 19: 403-10.

16. Hammond ME, Hayes DF, Dowsett M, Allred DC, Hagerty KL, Badve S, Fitzgibbons PL, Francis G, Goldstein NS, Hayes M, Hicks DG, Lester S, Love R, et al. American Society of Clinical Oncology/College Of American Pathologists guideline recommendations for immunohistochemical testing of estrogen and progesterone receptors in breast cancer. J Clin Oncol. 2010; 28: 2784-95.

17. Edge SB, Compton CC. The American Joint Committee on Cancer: the 7th edition of the AJCC cancer staging manual and the future of TNM. Ann Surg Oncol. 2010; 17:1471-4.

18. Acevedo F, Camus M, Sanchez C. Breast cancer at extreme ages - a comparative analysis in Chile. Asian Pac J Cancer Prev. 2015; 16:1455-1461. 